\title{
Impact of early adverse experience on complexity of adult-generated neurons
}

\author{
AT Leslie ${ }^{1,4}, K_{G}$ Akers $^{1,4}$, AD Krakowski ${ }^{1,2}$, SSD Stone ${ }^{1,2}$, M Sakaguchi $^{1}$, M Arruda-Carvalho $^{1,2}$ and PW Frankland ${ }^{1,2,3}$
}

New neurons continue to be generated in the dentate gyrus (DG) region of the hippocampus throughout adulthood, and abnormal regulation of this process has emerged as an endophenotype common to several psychiatric disorders. Previous research shows that genetic risk factors associated with schizophrenia alter the maturation of adult-generated neurons. Here, we investigate whether early adversity, a potential environmental risk factor, similarly influences adult neurogenesis. During the first 2 weeks of postnatal life, mice were subject to repeated and unpredictable periods of separation from their mothers. When the mice reached adulthood, pharmacological and retroviral labelling techniques were used to assess the generation and maturation of new neurons. We found that adult mice that were repeatedly separated from their mothers early in life had similar rates of proliferation in the DG, but had fewer numbers of cells that survived and differentiated into neurons. Furthermore, neurons generated in adulthood had less complex dendritic arborization and fewer dendritic spines. These findings indicate that early adverse experience has a long-lasting impact on both the number and the complexity of adult-generated neurons in the hippocampus, suggesting that the abnormal regulation of adult neurogenesis associated with psychiatric disorders could arise from environmental influence alone, or from complex interactions of environmental factors with genetic predisposition.

Translational Psychiatry (2011) 1, e35; doi:10.1038/tp.2011.38; published online 30 August 2011

\section{Introduction}

Accumulating evidence suggests a link between abnormal adult hippocampal neurogenesis and psychiatric disorders, including schizophrenia, depression and drug addiction, leading to the idea that aberrant integration of new neurons in the adult brain may contribute to mental illness. ${ }^{1,2}$ Consistent with this idea, mutations of genes associated with an increased risk of schizophrenia (for example, DISC1, RELN and NPAS3) alter the morphological maturation and migration of adult-generated neurons in the dentate gyrus (DG). ${ }^{3-5}$ However, although genes exert a strong influence on the likelihood of developing psychiatric disorders, early environmental factors, such as social exclusion from peers and caregiver abuse or neglect, also have a significant role. ${ }^{6,7}$

Here, we investigate whether adverse experiences early in life can lead to changes in the regulation of hippocampal neurogenesis during adulthood. Early adversity was modelled in mice using a chronic unpredictable maternal separation paradigm, ${ }^{8,9}$ in which mouse pups were separated from their mothers for $3 \mathrm{~h}$ a day during the first 2 postnatal weeks. When these mice reached adulthood, we assessed the proliferation, survival, differentiation and morphological maturation of new neurons in the DG. We found that, similar to some genetic manipulations, adverse early experiences have a long-lasting impact on both the number and the complexity of hippocampal neurons generated during adulthood.

\section{Materials and methods}

Mice. Mice were obtained from a cross between a primiparous 129Svev female mouse and a C57BI/6 male mouse (Taconic). Breeding occurred in our colony at the Hospital for Sick Children. The day of birth was designated as postnatal day $(P) 0$, and weaning occurred on P21. After weaning, mice were housed in groups of $2-5$, and maintained on a 12-h light/dark cycle (lights on at 0700 hours) with free access to food and water. All experimental procedures were approved by the Animal Care Committee at the Hospital for Sick Children.

Unpredictable maternal separation. Mouse pups were subjected to unpredictable maternal separation for $3 \mathrm{~h}$ a day from $\mathrm{P} 1$ to $\mathrm{P} 14$ ( $n=9$ litters). On each day, dams were removed from their home cages and individually placed in separate cages located in a different room. The home cages containing the pups were placed on heating pads to maintain the nest temperature at $30-31{ }^{\circ} \mathrm{C}$. The separation occurred randomly at one of the three possible times during the day (0900-1200, 1200-1500 or 1500-1800 hours). Control pups were left undisturbed in their home cages with their dam, except for weekly cage changes ( $n=10$ litters). There were no differences between separated and control group in litter size (separated: $7.6 \pm 0.5$ pups; control: $7.8 \pm 0.6$ pups; group effect: $P>0.05$ ) or sex ratio within litters (separated: $4.4 \pm 0.6$ males, $3.1 \pm 0.4$ females; control: $3.6 \pm 0.5$ males, $4.2 \pm 0.4$

\footnotetext{
${ }^{1}$ Neurosciences and Mental Health, Hospital for Sick Children, Toronto, Ontario, Canada; ${ }^{2}$ Institute of Medical Science, University of Toronto, Toronto, Ontario, Canada and ${ }^{3}$ Department of Physiology, University of Toronto, Toronto, Ontario, Canada

Correspondence: Dr PW Frankland, Neurosciences and Mental Health, Hospital for Sick Children, 555 University Avenue, Toronto, Ontario, M5G 1X8 Canada. E-mail: paul.frankland@sickkids.ca

${ }^{4}$ These authors contributed equally to this work.

Keywords: adult neurogenesis; dentate gyrus; depression; hippocampus; maternal separation; schizophrenia

Received 29 July 2011; accepted 3 August 2011
} 
females; group $\times$ sex interaction: $P>0.05)$. To reduce the possibility of litter effects on dependent measures, ${ }^{10}$ the separated and control mice used for each experiment were sampled from several different litters (proliferation $n=15$ litters; survival $n=14$ litters; morphology $n=8$ litters).

5-Bromo-2'-deoxyuridine (BrdU) injection. Cells undergoing division were labelled with BrdU, a thymidine analog that incorporates into the DNA of cells during the S-phase of the cell cycle. BrdU was dissolved in $0.1 \mathrm{M}$ phosphatebuffered saline (PBS) at a concentration of $10 \mathrm{mg} \mathrm{ml}^{-1}$. At $\mathrm{P} 60$, mice received two injections of BrdU per day (100 $\mathrm{mg} \mathrm{kg}^{-1} ; 5 \mathrm{~h}$ apart) for 3 consecutive days. To assess cell proliferation, mice were perfused $24 \mathrm{~h}$ after the last BrdU injection (separated: $n=15,7$ male, 8 female; control: $n=15,6$ male, 9 female). To assess cell survival and differentiation, mice were perfused 4 weeks after the last BrdU injection (separated: $n=16,9$ male, 7 female; control: $n=18,9$ male, 9 female). After deep anesthesia with chloral hydrate, mice were perfused transcardially with PBS followed by $4 \%$ paraformaldehyde. Brains were removed and placed in $4 \%$ paraformaldehyde for $48 \mathrm{~h}$ at $4{ }^{\circ} \mathrm{C}$ and then transferred to PBS. Serial coronal sections $(40 \mu \mathrm{m})$ were obtained across the entire anterior-posterior extent of the hippocampus using a vibratome. Sections were stored in PBS with $0.01 \%$ sodium azide at $4{ }^{\circ} \mathrm{C}$.

Green fluorescent protein (GFP) retrovirus infusion. New neurons were labelled by CAG promoter-driven GFP expression, following infection with a replication-deficient retroviral vector based on the Moloney murine leukemia virus. ${ }^{11}$ The retrovirus was prepared in our laboratory by transfecting Plat-gp cells with plasmids containing an amphotropic envelope (vsvg) and the transgene (pCAGGFP). Ultra-high-speed centrifugation was used to concentrate the virus into a high-titer solution $\left(5 \times 10^{8-9}\right.$ infection units $\mathrm{ml}^{-1}$ ). At P60, mice (separated: $n=5,3$ male, 2 female; control: $n=5,2$ male, 3 female) were treated with atropine $\left(0.1 \mathrm{mg} \mathrm{kg}^{-1}\right)$ and anesthetized with chloral hydrate $\left(400 \mathrm{mg} \mathrm{kg}^{-1}\right)$. Using stereotaxic procedures, $1.0 \mu \mathrm{l}$ of the retrovirus was infused into the DG bilaterally $(-2.2 \mathrm{~mm} \mathrm{AP}$, $\pm 1.6 \mathrm{~mm} \mathrm{ML}$ and $2.0 \mathrm{~mm} \mathrm{DV}$ relative to bregma). The retrovirus was delivered using a glass micropipette, and a pump maintained the infusion rate at $0.15 \mu \mathrm{min}^{-1}$. The pipette was left in place for $5 \mathrm{~min}$ after each infusion. Mice were postoperatively treated with ketoprofen $\left(5 \mathrm{mg} \mathrm{kg}^{-1}\right)$. Mice were perfused 4 weeks after retrovirus infusion. Serial coronal sections $(50 \mu \mathrm{m})$ were obtained across the entire anteriorposterior extent of the hippocampus using a vibratome.

Immunohistochemistry. For BrdU labelling, free-floating sections were treated with $1 \mathrm{~N} \mathrm{HCl}$ at $45^{\circ} \mathrm{C}$ for $30 \mathrm{~min}, 1 \%$ $\mathrm{H}_{2} \mathrm{O}_{2}$ at room temperature (RT) for $15 \mathrm{~min}$ and $0.2 \mathrm{M}$ glycine in PBS at RT for $10 \mathrm{~min}$. Sections were incubated with the primary antibody (rat anti-BrdU, 1:1000, monoclonal antibody, Accurate Chemicals, Westbury, NY, USA) at RT overnight and the secondary antibody (Alexa-488 goat antirat, 1:1000, Molecular Probes, Carlsbad, CA, USA) at RT for $2 \mathrm{~h}$. For the 4-week survival group, sections were also labelled with neuronal-specific nuclear protein (NeuN) using an additional primary antibody (mouse anti-NeuN, 1:1000, Chemicon, Billerica, MA, USA) and a secondary antibody (Alexa-568 goat anti-mouse, 1:1000, Molecular Probes). Antibodies were diluted in blocking solution (2.5\% bovine serum albumin, 5\% normal goat serum and $0.3 \%$ Triton $X-100$ in PBS). Sections were counterstained with 4',6-diamidino-2-phenylindole (1:10000) and mounted on slides with Permafluor anti-fade medium (ThermoScientific, Waltham, MA, USA).

For GFP labelling, free-floating sections were incubated with the primary antibody (rabbit anti-GFP, 1:500, Invitrogen, Carlsbad, CA, USA) at RT overnight and the biotinylated secondary antibody (goat anti-rabbit, 1:1000, Jackson Immuno Research, West Grove, PA, USA) at RT for $2 \mathrm{~h}$. Cells were visualized using the avidin-biotin-peroxidase complex (Vector Laboratories, Burlingame, CA, USA), followed by $3,3^{\prime}$-diaminobenzidine. Sections were mounted on gel-coated slides, dehydrated and coverslipped with Cytoseal (Richard-Allan Scientific, Kalamazoo, MI, USA).

BrdU quantification. BrdU-labelled cells were quantified on a Nikon (Melville, NY, USA) fluorescent microscope with a $\times 40$ objective. Using a modified stereological procedure, $\mathrm{BrdU}+$ cells in the subgranular zone and granule cell layer of the DG were counted manually from every sixth section, and an estimate of the total number of BrdU + cells in the DG was obtained by multiplying the average number of BrdU + cells per section by the number of $40-\mu \mathrm{m}$ sections comprising the entire DG. ${ }^{12}$ For the 4-week survival group, BrdU + /NeuN + cells were also counted manually and were expressed as a proportion of the total number of BrdU + cells.

Morphological analysis. Morphological analysis of adultgenerated granule neurons was performed on an Olympus (Tokyo, Japan) light microscope using a $\times 100$ objective. GFP + neurons in the granule cell layer of the DG were selected for analysis if they had at least one third-order dendrite. Using NeuroLeucida software, the entire dendritic arbor, including dendritic spines, was traced. A series of concentric spheres spaced $20 \mu \mathrm{m}$ apart was centered on the soma, and the number of times that each sphere was intersected by a dendrite and the total dendritic length within each sphere were quantified. ${ }^{13}$ Spine density was calculated by dividing the spine number by dendritic length. Between one to seven neurons were traced per mouse, and dependent measures were averaged within each mouse.

Statistical analysis. Data were subjected to either two-way analysis of variance with group and sex as between-subject factors or three-way analysis of variance with group and sex as between-subject factors and distance from soma as a within-subject factor We found no significant effects involving sex; therefore this factor was dropped from the analysis.

\section{Results}

To determine whether early life adversity reduces the number of adult-generated cells in the DG, we injected adult mice with BrdU to label proliferating cells. At 1 day after injection, maternally separated and control mice had similar numbers of 
proliferating cells (Figure 1a; group effect: $P>0.05$ ). However, at 4 weeks after injection, maternally separated mice had fewer surviving cells (Figure $1 \mathrm{~b}$; group effect: $F_{1,32}=7.88$, $P=0.008$ ) and a smaller proportion of surviving cells that expressed NeuN, a marker of mature neurons (Figure 1c;

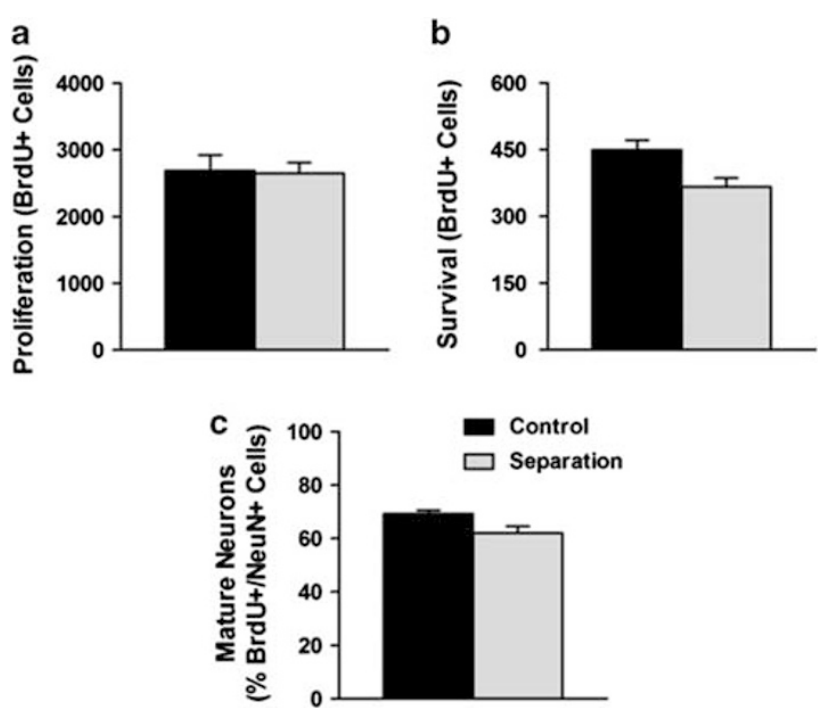

Figure 1 Adult-generated cells in the DG were labelled by injections of BrdU. Maternal separation did not affect the number of proliferating cells 1 day after BrdU injection (a), but reduced the number of cells that survived for 4 weeks (b) and differentiated into neurons (c). group effect: $F_{1,32}=6.90, P=0.013$ ), indicating that maternal separation persistently reduces the survival of adult-generated granule neurons in the DG.

Next, to examine whether early life adversity also affects the maturation of adult-generated neurons, we labelled proliferating cells in adult mice by microinfusion of a GFP-expressing retrovirus into the $D G$. The robust and persistent expression of GFP in the soma and processes allowed for the reconstruction and detailed morphological analysis of infected neurons at a later time point. The complexity of dendritic arborization was assessed by quantifying the number of dendritic intersections and dendritic length as a function of distance from the soma using Sholl analysis (Figures $2 a$ and $b$ ).

We found that repeated and unpredictable periods of separation from the mother led to profound changes in the complexity of adult-generated granule neurons. Four weeks post infection, new neurons in maternally separated mice had fewer dendritic intersections (Figure 2c; group effect: $F_{1,8}=9.09, \quad P=0.017 ; \quad$ group $\times$ distance interaction: $\left.F_{14,112}=3.73, \quad P<0.001\right)$ and reduced dendritic length (Figure 2d; group effect: $F_{1,8}=7.50, P=0.026$; group $\times$ distance interaction: $F_{14,112}=2.71, P=0.002$ ) compared with control mice. Although spine density was unaffected (spines per $10 \mu \mathrm{m}$; separation: $5.54 \pm 0.60$; control: $5.93 \pm 0.24$; group effect: $P>0.05)$, the reduction in dendritic complexity resulted in fewer total numbers of spines per neuron (Figure 2e; group effect: $\left.F_{1,8}=5.59, P=0.046\right)$, suggesting that adult-generated granule neurons in maternally separated mice form fewer synapses with incoming fibers.
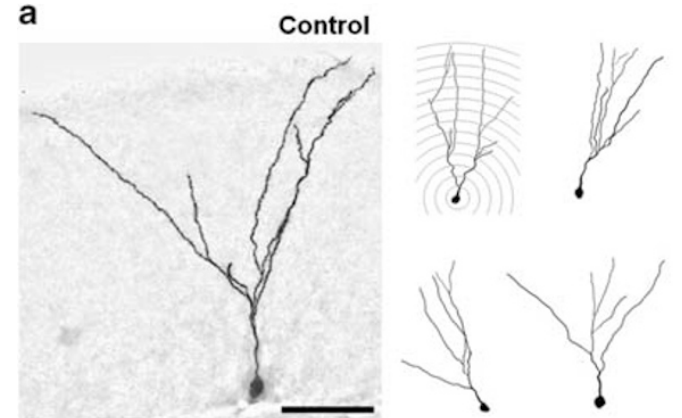

b
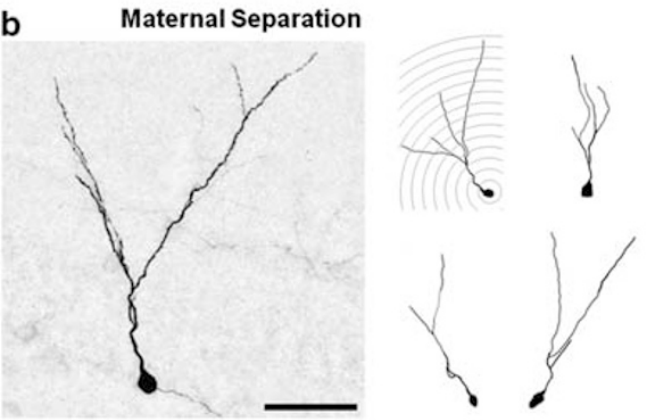
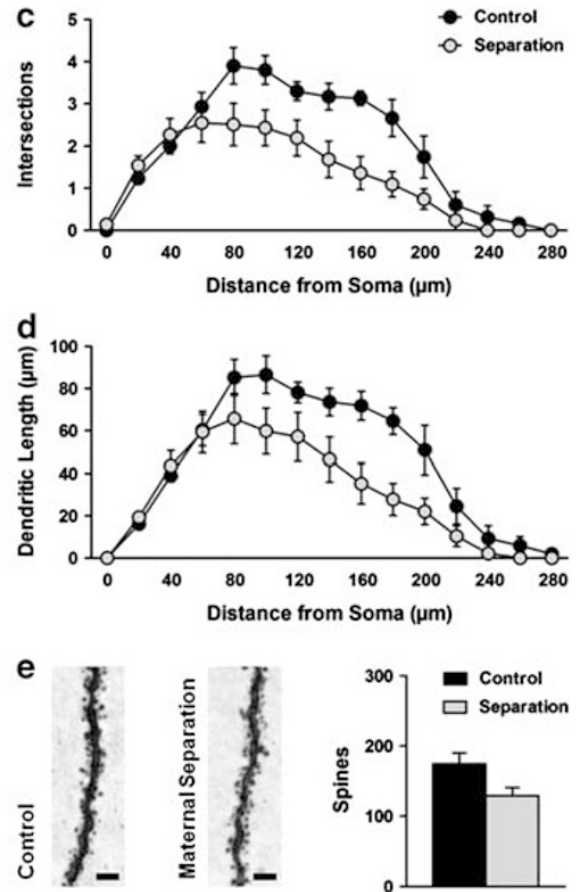

Figure 2 Adult-generated neurons in the DG were labelled by a GFP-expressing retrovirus and visualized using 3,3'-diaminobenzidine staining 4 weeks after infection. Representative images of adult-generated granule neurons from (a) control mice and (b) mice that were repeatedly and unpredictably separated from their mothers during the first 2 weeks of life (left: $\times 20$ magnification, scale bar $=50 \mu \mathrm{m}$; right: manual tracings). Sholl analysis of adult-generated neurons revealed that maternal separation reduced the complexity of dendritic arborization, as evidenced by (c) fewer intersections and (d) less dendritic length. (e) Representative images of dendritic spines (scale bar $=3 \mu \mathrm{m}$ ) from control and maternally separated mice. Maternal separation reduced the total number of spines per neuron. 


\section{Discussion}

Previous studies in rodents report that early adversity, in the form of separation from the mother during the initial postnatal weeks, alters the number and morphology of developmentally generated DG neurons. ${ }^{14-17}$ Here, we show that the effects of early adversity on the generation and maturation of new DG neurons persist long after the adverse events initially take place. Specifically, rodents that experience maternal separation early in life not only possess fewer new DG neurons during adulthood, ${ }^{16,18-21}$ but also possess adult-generated DG neurons with less complex dendritic arborization and fewer dendritic spines. Early adverse experiences, therefore, can exert a long-lasting influence on the regulation of neurogenesis during adulthood, potentially interfering with hippocampal function and leading to behavioral abnormalities later in life. Indeed, rodents that experience maternal separation early in life show several behavioral disturbances during adulthood, including cognitive deficits, ${ }^{16,19,22}$ decreased sociability, ${ }^{23,24}$ increased anxiety, ${ }^{22,25,26}$ and the presence of depression- and schizophrenia-like behaviors, ${ }^{22,23,27,28}$ which is consistent with the possibility that the neurobiological consequences of early adverse experiences may contribute to the onset of psychiatric symptoms later in life.

Our finding that the influence of early maternal separation on adult neurogenesis is observable long after the adverse experiences have taken place suggests that the effects of early adversity may be mediated through epigenetic modifications of DNA. ${ }^{29,30}$ Such modifications could result in persistent changes in levels of stress hormones or neurotrophic factors that are known to influence the generation and growth of new neurons in the adult brain. ${ }^{31-33}$ For instance, adult rodents that experienced maternal separation during the initial postnatal weeks have higher circulating levels of corticosterone $\mathrm{e}^{34-36}$ and reduced hippocampal levels of brain-derived neurotrophic factor, ${ }^{21,35,37}$ nerve growth factor ${ }^{34}$ and neurotophin- $3,{ }^{34}$ thereby possibly resulting in reductions in the number and complexity of newly generated DG neurons. Furthermore, maternal separation and poor maternal care early in life have been found to produce changes in DNA methylation ${ }^{38-40}$ that are passed onto the next generation of offspring, ${ }^{8}$ suggesting that the impact of early adversity on the brain can persist throughout the lifespan and even into future generations.

Whereas previous studies demonstrate that mutations of genes associated with increased risk of schizophrenia alter the number and complexity of adult-generated neurons in the $\mathrm{DG},{ }^{3-5}$ we show here that early adversity, an environmental risk factor, can produce similar changes. The abnormal regulation of adult neurogenesis following early adverse experiences could contribute to psychopathology by disrupting the balance between pattern separation and pattern completion along the entorhinal cortex-DG-CA3 pathway, leading to spurious associations, and hence the formation of memories with psychotic content. ${ }^{41}$ Our finding that neurogenesis during adulthood can be shaped by experiences early in life suggests that the abnormalities in adult neurogenesis observed in individuals with schizophrenia, including fewer new hippocampal cells in vivo ${ }^{42}$ and reduced connectivity of new neurons reprogrammed from fibroblasts in vitro, ${ }^{43}$ could arise from environmental influence alone or from complex interactions of environmental factors with genetic predisposition.

\section{Conflict of interest}

The authors declare no conflict of interest.

Acknowledgements. We thank Leonardo Restivo and Mika Yamamoto for technical assistance, and Sheena Josselyn for comments on the manuscript. This work was supported by a grant from the Canadian Institutes of Health Research (CIHR, MOP86762) to PWF. KGA and SSDS were supported by fellowships from CIHR. ADK was supported by a scholarship from the Natural Sciences and Engineering Research Council (NSERC). MS was supported by a fellowship from the Japanese Society for the Promotion of Science. MA-C was supported by scholarships from the Ontario Graduate Scholarship Program and the Hospital for Sick Children.

1. Eisch AJ, Cameron HA, Encinas JM, Meltzer LA, Ming GL, Overstreet-Wadiche LS. Adult neurogenesis, mental health, and mental illness: hope or hype? J Neurosci 2008; 28: 11785-11791.

2. Kempermann G, Krebs J, Fabel K. The contribution of failing adult hippocampal neurogenesis to psychiatric disorders. Curr Opin Psychiatry 2008; 21: 290-295.

3. Duan X, Chang JH, Shayo G, Faulkner RL, Young Kim J, Kitabatake Y et al. DisruptedIn-Schizophrenia 1 regulates integration of newly generated neurons in the adult brain. Cell 2007; 130: 1146-1158.

4. Pujades L, Gruart A, Bosch C, Delgado L, Teixeira CM, Rossi D et al. Reelin regulates postnatal neurogenesis and enhances spine hypertrophy and long-term potentiation. J Neurosci 2010; 30: 4636-4649.

5. Pieper AA, Xie S, Capota E, Estill SJ, Zhong J, Long JM et al. Discovery of a proneurogenic, neuroprotective chemical. Cell 2010; 142: 39-51.

6. van Os J, Kenis G, Rutten BPF. The environment and schizophrenia. Nature 2010; 468: 203-212.

7. Brown AS. The environment and susceptibility to schizophrenia. Progress Neurobiol 2011; 93: 23-58

8. Franklin TB, Russig H, Weiss IC, Graff J, Linder N, Michalon A et al. Epigenetic transmission of the impact of early stress across generations. Biol Psychiatry 2010; 68: 408-415.

9. Weiss IC, Franklin TB, Vizi S, Mansuy IM. Inheritable effect of unpredictable maternal separation on behavioral responses in mice. Front Behav Neurosci 2011; 5: 3.

10. Abbey H, Howard E. Statistical procedure in developmental studies on species with multiple offspring. Dev Psychobiol 1972; 6: 329-335.

11. Tashiro A, Zhao C, Gage FH. Retrovirus-mediated single-cell gene knockout technique in adult newborn neurons in vivo. Nat Protoc 2006; 1: 3049-3055.

12. Kee N, Teixeira CM, Wang AH, Frankland PW. Preferential incorporation of adultgenerated granule cells into spatial memory networks in the dentate gyrus. Nat Neurosci 2007; 10: 355-362.

13. Sholl DA. Dendritic organization in the neurons of the visual and motor cortices of the cat. $J$ Anat 1953; 87: 387-406.

14. Oomen CA, Soeters H, Audureau N, Vermunt L, van Hasselt FN, Manders EMM et al. Early maternal deprivation affects dentate gyrus structure and emotional learning in adult female rats. Psychopharmacology 2011; 214: 249-260.

15. Oomen CA, Girardi CEN, Cahyadi R, Verbeek EC, Krugers H, Joels M et al. Opposite effects of early maternal deprivation on neurogenesis in male versus female rats. PLOS ONE 2009; 4: e3675.

16. Oomen CA, Soeters H, Audureau N, Vermunt L, van Hasselt FN, Manders EMM et al. Severe early life stress hampers spatial learning and neurogenesis, but improves hippocampal synaptic plasticity and emotional learning under high-stress conditions in adulthood. J Neurosci 2010; 30: 6635-6645.

17. Nair A, Vadodaria KC, Banerjee SB, Benekareddy M, Dias BG, Duman RS et al. Stressorspecific regulation of distinct brain-derived neurotrophic factor transcripts and cyclic AMP response element-binding protein expression in the postnatal and adult rat hippocampus. Neuropsychopharmacology 2007; 32: 1504-1519.

18. Kikusui T, Ichikawa S, Mori Y. Maternal deprivation by early weaning increases corticosterone and decreases hippocampal BDNF and neurogenesis in mice. Psychoneuroendocrinology 2009; 34: 762-772.

19. Hulshof HJ, Novati A, Sgoifo A, Luiten PGM, den Boer JA, Meerlo P. Maternal separation decreases adult hippocampal cell proliferation and impairs cognitive performance but has little effect on stress sensitivity and anxiety in adult Wistar rats. Behav Brain Res 2011; 216: $552-560$. 
20. Mirescu C, Peters JD, Gould E. Early life experience alters response of adult neurogenesis to stress. Nat Neurosci 2004; 7: 841-846.

21. Aisa B, Elizalde N, Tordera R, Lasheras B, Del Rio J, Ramirez MJ. Effects of neonatal stress on markers of synaptic plasticity in the hippocampus: implications for spatial memory. Hippocampus 2009; 19: 1222-1231.

22. Aisa B, Tordera R, Lasheras B, Del Rio J, Ramirez MJ. Cognitive impairment associated to HPA axis hyperactivity after maternal separation in rats. Psychoneuroendocrinol 2007; 32 256-266.

23. Veenema AH, Blume A, Niederle D, Buwalda B, Neumann ID. Effects of early life stress on adult male aggression and hypothalamic vasopression and serotonin. Eur J Neurosci2006; 24: $1711-1720$

24. Bouet $\mathrm{V}$, Lecrux B, Tran G, Freret $T$. Effect of pre- versus post-weaning environmental disturbances on social behaviour in mice. Neurosci Lett 2011; 488: 221-224.

25. Romeo RD, Mueller A, Sisti HM, Ogawa S, McEwen BS, Brake WG. Anxiety and fear behaviors in adult male and female $\mathrm{C} 57 \mathrm{BL} / 6$ mice are modulated by maternal separation. Horm Behav 2003; 43: 561-567.

26. Wigger A, Neumann ID. Periodic maternal deprivation induces gender-dependen alterations in behavioral and neuroendocrine responses to emotional stress in adult rats. Physiol Behav 1999; 66: 293-302.

27. Ellenbroek BA, de Bruin NM, van Den Kroonenburg PT, van Luijtelaar EL, Cools AR. The effects of early maternal deprivation on auditory information processing in adult Wistar rats. Biol Psychiatry 2004; 55: 701-707.

28. Garner B, Wood SJ, Pantelis C, van den Buuse M. Early maternal deprivation reduces prepulse inhibition and impairs spatial learning ability in adulthood: no furthe effect of post-pubertal chronic corticosterone treatment. Behav Brain Res 2007; 176: 323-332.

29. Zhang T-Y, Meaney MJ. Epigenetics and the environmental regulation of the genome and its function. Annu Rev Psychol 2010; 61: 439-466.

30. Szyf M. The early life social environment and DNA methylation: DNA methylation mediating the long-term impact of social environments early in life. Epigenetics 2011; 6: 971-978.

31. Mirescu C, Gould E. Stress and adult neurogenesis. Hippocampus 2006; 16: 233-238.

32. McEwen BS. Effects of adverse experiences for brain structure and function. Biol Psychiatry 2000; 48: 721-731.

33. Alleva E, Francia N. Psychiatric vulnerability: suggestions from animal models and role of neurotrophins. Neurosci Biobehav Rev 2009; 33: 525-536.
34. Marais L, van Rensburg SJ, van Zyl JM, Stein DJ, Daniels WMU. Maternal separation of rat pups increases the risk of developing depressive-like behavior after subsequent chronic stress by altering corticosterone and neurotrophin levels in the hippocampus. Neurosci Res 2008; 61: 106-112.

35. Lippmann M, Bress A, Nemeroff CB, Plotsky PM, Monteggia LM. Long-term behavioural and molecular alterations associated with maternal separation in rats. Eur J Neurosci 2007; 25: 3091-3098.

36. Plotsky PM, Meaney MJ. Early, postnatal experience alters hypothalamic corticotropinreleasing factor (CRF) mRNA, median eminence CRF content and stress-induced release in adult rats. Brain Res Mol Brain Res 1993; 18: 195-200.

37. Roceri M, Hendriks W, Racagni G, Ellenbroek BA, Riva MA. Early maternal deprivation reduces the expression of BDNF and NMDA receptor subunits in rat hippocampus. $\mathrm{Mol}$ Psychiat 2002; 7: 609-616.

38. Roth TL, Lubin FD, Funk A, Sweatt JD. Lasting epigenetic influence of early-life adversity on the BDNF gene. Biol Psychiatry 2009; 65: 760-769.

39. Weaver ICG, Cervoni N, Champagne FA, D'Alessio AC, Sharma S, Seckl JR et al. Epigenetic programming by maternal behavior. Nat Neurosci 2004; 7: 847-854.

40. Murgatroyd C, Patchev AV, Wu Y, Micale V, Bockmuhl Y, Fischer D et al. Dynamic DNA methylation programs persistent adverse effects of early-life stress. Nat Neurosci 2009; 12: 1559-1566.

41. Tamminga $C A$, Stan AD, Wagner AD. The hippocampal formation in schizophrenia. Am J Psychiatry 2010; 167: 1178-1193.

42. Reif A, Fritzen S, Finger M, Strobel A, Lauer M, Schmitt A et al. Neural stem cell proliferation is decreased in schizophrenia, but not in depression. Mol Psychiatry 2006; 11: 514-522.

43. Brennard KJ, Simone A, Jou J, Gelboin-Burkhart C, Tran N, Sangar S et al. Modelling schizophrenia using human induced pluripotent stem cells. Nature 2011; 473: 221-225.$$
\text { (c) }
$$

Translational Psychiatry is an open-access journal published by Nature Publishing Group. This work is licensed under the Creative Commons Attribution-Noncommercial-No Derivative Works 3.0 Unported License. To view a copy of this license, visit http://creativecommons.org/licenses/by-nc-nd/3.0/ 